\title{
PENGARUH KUALITAS PELAYANAN, KUALITAS PRODUK DAN PROMOSI TERHADAP KEPUTUSAN PEMBELIAN PADA OPTIK TUNGGAL SEMPURNA CABANG LIPPO MALL KEMANG
}

\author{
Fitriani, Lucy Nancy* \\ *Dosen Tetap Program S1 Jurusan Manajemen Fakultas Ekonomi Universitas Satya Negara Indonesia \\ mamaolgalucy@yahoo.co.id; pandafitriani696@gmail.com
}

\begin{abstract}
This study aims to determine the effect of Service Quality, Product Quality and Promotion on the purchase decision. used in the research is quantitative methods and assessment of the results of this study based on the answers to the questionnaire given to respondents using Likert Scale. The population in this study is all customers at Optik Tunggal Sempurna and sample in this study is amounted to 58 respondents. Methods of analysis in this research using descriptive analysis, The Instrument (Validity and Reability), Classical Assumption Test (Normality, Multicoloniarity, Heteroskidasity, and Autocorrelation), Corelattion, Linier regression analysis, t test, $F$ test and Determinant coefficient $R^{2}$.

The results of the t test (partially), has obtained results that variable Product Quantity is significant on the purchase decision of PT.Optik Tunggal Sempurna. While the variable Service Quality and Promotion have no effect and does not significantly influence the purchase decision of PT.Opiik Tunggal Sempurna. From test $f$ (simultaneously), the result that the third variable and significant influence on the purchase decision of Optik Tunggal Sempurna
\end{abstract}

Keywords : Service Quality, Service Product, Promotion and Purchase Decision.

\section{PENDAHULUAN}

\section{Latar Belakang}

Saat ini banyak dan beraneka ragam usaha yang berkembang. Dunia mode pun sekarang di dalam negeri sangat berpengaruh bagi masyarakat termasuk mode kacamata dan softlens. Oleh karena itu banyak optik bermunculan. Optik sangat berpengaruh dalam bidang pendidikan, kesehatan, dan perkantoran. Optik sendiri menjual kacamata dan lensa dimana lensa merupakan jendela dunia. Mata manusia adalah alat indra penglihatan penting bagi manusia. Tingginya aktivitas serta banyaknya faktor-faktor yang mempengaruhi gangguan tajam penglihatan terhadap seseorang mengakibatkan tingginya angka kelainan reflaksi, dengan kondisi tersebut dijelaskan bahwa seseorang membutuhkan kacamata sebagai alat bantu penglihatan karena matanya sudah tidak berfungsi normal lagi. Frame kacamata atau bingkai kacamata saat ini bukan lagi digunakan sebagai alat penglihatan saja tetapi sudah menuju ke arah kosmetik atau fashion, dan juga penggunaan kacamata sudah lebih ke arah kesehatan dan keselamatan dari bahaya kecelakaan kerja.

Perusahaan yang cerdas berusaha untuk memahami proses keputusan pembelian pelanggan secara penuh, semua pengalaman mereka dalam pembelanjaan, memilih, menggunakan dan bahkan menyingkirkan produk. Konsumen melalui lima tahap :pengenalan masalah, pencarian informasi, evaluasi alternatif, keputusan pembelian dan perilaku pasca pembelian dimulai jauh sebelum pembelian aktual dan mempunyai konsekuensi dalam waktu lama setelahnya. 
Berkaitan dengan teori Kualitas Pelayanan, memiliki keseluruhan fitur dan sifat produksi atau pelayanan yang berpengaruh pada kemampuannya untuk memuaskan kebutuhan yang di nyatakan atau tersirat. Kualitas jasa perusahaan diuji pada setiap pelaksanaan jasa.berdasarkan skala SERVQUAL terdapat lima determinan Kualitas Jasa yaitu Keandalan, Responsivitas, Jaminan, Empati, dan Wujud. Ada zona toleransi atau kisaran dimana dimensi jasa dianggap memuaskan. Ditandai dengan tingkat kesedian minimum konsumen untuk menerima dan tingkat dimana mereka percaya bahwa jasa bisa dan harus dihantarkan kepada mereka.

Kualitas Produk yang ditawarkan Optik Tunggal Sempurna adalah lensa yang tahan lama tidak mudah baret dan rusak karena di import bahan lensa dari Jerman dan design sendiri di Optik Tunggal Laboratorium, serta karakteristik dari produk Oakley yang memiliki teknologi Crosslink yaitu temple tangkai kacamata dapat di ganti sesuai selera jadi dapat di sesuaikan dengan aktifitas konsumen itu sendiri, serta tampilan kacamata yang selalu up todate dan menggunakan kemasan yang mewah menciptakan nilai lebih untuk produk itu sendiri.

Bentuk Promosi yang dilakukan Optik Tunggal Sempurna dalam sales promotion adalah dengan memberikan discount setiap bulan yang berbeda-beda, memberikan satu coupons setiap transaksi minimal Rp.2.000.000 untuk dapat di tukarkan berupa nomer undian, lalu memberikan free trail contact lens gratis . Untuk meningkatkan Citra perusahaan Promosi yang di lakukan mengadakan berbagai events spesial di tempat-tempat sosial, sekolah-sekolah serta di mall-mall besar di Jakarta, memberikan sponsor pada event-event yang diadakan di mall, ikut serta mensponsori dalam event-event yang sedang berlangsung.

Penelitian-penelitian sebelumnya masih menunjukkan hasil yang berbeda. Berikut ini merupakan penelitian-penelitian sebelumnya terkait faktor-faktor yang mempengaruhi variabel Keputusan Pembelian

Tabel 1 Research Gap

\begin{tabular}{|l|l|l|}
\hline Variabel & Peneliti & Hasil Penelitian \\
\hline $\begin{array}{l}\text { Kualitas } \\
\text { Pelayanan }\end{array}$ & Agus Sriyanto(2015) & Berpengaruh terhadap Keputusan Pembelian \\
\hline \multirow{3}{*}{$\begin{array}{l}\text { Kualitas } \\
\text { Produk }\end{array}$} & Rahmi Rosita (2016) & Tidak Berpengaruh terhadap Keputusan Pembelian \\
\hline Promosi & $\begin{array}{l}\text { Novemy Triyandari } \\
\text { Nugroho (2015) }\end{array}$ & Berpengaruh terhadap Keputusan Pembelian \\
\cline { 2 - 3 } & $\begin{array}{l}\text { Josiel Driand } \\
\text { Pandensolang(2015) }\end{array}$ & Tidak Berpengaruh terhadap Keputusan Pembelian \\
& $\begin{array}{l}\text { Novemy Triyandari } \\
\text { Nugroho(2015) }\end{array}$ & Berpengaruh terhadap Keputusan Pembelian \\
\cline { 2 - 3 } & $\begin{array}{l}\text { Maulana Umaternate, } \\
\text { Willem JF Tumbuan, } \\
\text { Rita Taroreh(2014) }\end{array}$ & Tidak Berpengaruh terhadap Keputusan Pembelian \\
\hline
\end{tabular}

Sumber : diolah Penulis, 2018

\section{KERANGKA PEMIKIRAN TEORITIS}

\section{Kualitas Pelayanan}

Kualitas Pelayanan adalah kondisi dinamis yang berhubungan dengan produk, jasa, sumber daya manusia, proses dan lingkungan yang memenuhi atau melebihi harapan. 


\section{Kualitas Produk}

Kualitas Produk adalah karakteristik produk atau layanan yang sesuai dengan kemampuannya untuk memenuhi kebutuhan pelanggan yang dinyatakan atau tersirat. Produk adalah segala sesuatu yang dapat ditawarkan kepada pasar untuk memuaskan suatu keingian atau kebutuhan, termasuk barang fisik, jasa, pengalaman, acara, tempat,properti, organisasi, informasi dan ide.

\section{Promosi}

Promosi adalah berbagai cara untuk menginformasikan, membujuk dan menginginkan konsumen secara langsung maupun tidak langsung tentang suatu produk atau brand yang dijual.

\section{Keputusan Pembelian}

Keputusan Pembelian adalah keputusan pembelian konsumen akhir perorangan dan rumah tangga yang membeli barang dan jasa untuk konsumsi pribadi.

Berikut ini merupakan penelitian-penelitian sebelumnya :

Tabel 2 Peneltian Terdahulu

\begin{tabular}{|c|c|c|c|c|}
\hline Tahun & Peneliti & variabel & $\begin{array}{l}\text { Jenis } \\
\text { Penelitian }\end{array}$ & Hasil Penelitian \\
\hline 2015 & $\begin{array}{l}\text { Agus } \\
\text { Sriyanto }\end{array}$ & $\begin{array}{l}\text { Kualitas } \\
\text { Layanan, Ekuitas } \\
\text { Merek Promosi }\end{array}$ & $\begin{array}{l}\text { Regresi } \\
\text { Linier } \\
\text { Berganda }\end{array}$ & $\begin{array}{l}\text { Ada pengaruh positif signifikan dari variabel } \\
\text { Kualitas Layanan, Ekuitas Merek dan Promosi } \\
\text { terhadap keputusan Pembelian Produk Lion Star di } \\
\text { Modern Market jakarta. }\end{array}$ \\
\hline 2016 & $\begin{array}{l}\text { Rahmi } \\
\text { Rosita }\end{array}$ & $\begin{array}{l}\text { Lokasi } \\
\text { Kelengkapan } \\
\text { produk, Kualitas } \\
\text { Produk, } \\
\text { Pelayanan, Harga, } \\
\text { Kenyamanan } \\
\text { Berbelanja }\end{array}$ & $\begin{array}{l}\text { Regresi } \\
\text { Linier } \\
\text { Berganda }\end{array}$ & $\begin{array}{l}\text { Tidak berpengaruh Kualitas Pelayanan Terhadap } \\
\text { Keputusan Pembelian, Terdapat pengaruh positif } \\
\text { Lokasi terhadap Keputusan Pembelian, Terdapat } \\
\text { pengaruh positif Kelengkapan Produk terhadap } \\
\text { Keputusan Pembelian, Terdapat Pengaruh Positif } \\
\text { Kualitas Produk terhadap Keputusan Pembelian, } \\
\text { Terdapat pengaruh positif Harga terhadap Keputusan } \\
\text { Pembelian, Terdapat pengaruh positif Kenyamanan } \\
\text { Berbelanja terhadap Keputusan Pembelian }\end{array}$ \\
\hline 2015 & $\begin{array}{l}\text { Novemy } \\
\text { Triyandari } \\
\text { Nugroho }\end{array}$ & $\begin{array}{l}\text { Kualitas Produk, } \\
\text { Harga Promosi }\end{array}$ & $\begin{array}{l}\text { Regresi } \\
\text { Linier } \\
\text { Berganda }\end{array}$ & $\begin{array}{l}\text { Ada pengaruh positif Kualitas Produk, Harga, dan } \\
\text { Promosi terhadap Keputusan Pembelian, }\end{array}$ \\
\hline 2015 & $\begin{array}{l}\text { Josiel } \\
\text { Driand } \\
\text { Pandensolan } \\
\text { g }\end{array}$ & $\begin{array}{l}\text { Diferensiasi, } \\
\text { Kualitas Produk } \\
\text { Ekuitas Merek }\end{array}$ & $\begin{array}{l}\text { Regresi } \\
\text { Linier } \\
\text { Berganda }\end{array}$ & $\begin{array}{l}\text { Menyatakan bahwa Kualitas Produk dan Ekuitas } \\
\text { Merek berpengaruh Negatif terhadap Keputusan } \\
\text { Pembelian, Terdapat pengaruh positif pada variabel } \\
\text { Diferensiasi terhadap keputusan Pembelian. }\end{array}$ \\
\hline 2014 & $\begin{array}{l}\text { Maulana } \\
\text { M.I.Umater } \\
\text { nate, } \\
\text { Willem } \\
\text { JF.Alfa } \\
\text { Tumbuan, } \\
\text { Rita Taroreh }\end{array}$ & $\begin{array}{l}\text { Promosi, Harga, } \\
\text { Inovasi }\end{array}$ & $\begin{array}{l}\text { Regresi } \\
\text { Linier } \\
\text { Berganda }\end{array}$ & $\begin{array}{l}\text { Pengaruh negatif signifikan variabel Promosi } \\
\text { terhadap Keputusan Pembelian, Terdapat pengaruh } \\
\text { negatif variabel Harga terhadap Keputusan } \\
\text { pembelian, Terdapat pengaruh positif variabel } \\
\text { Inovasi terhadap Keputusan Pembelian. }\end{array}$ \\
\hline
\end{tabular}

Sumber: dari berbagai Jurnal Publikasi Ilmiah

Berdasarkan penjelasan diatas maka dapat dikembangkan kerangka pemikiran teoritis seperti dibawah ini 


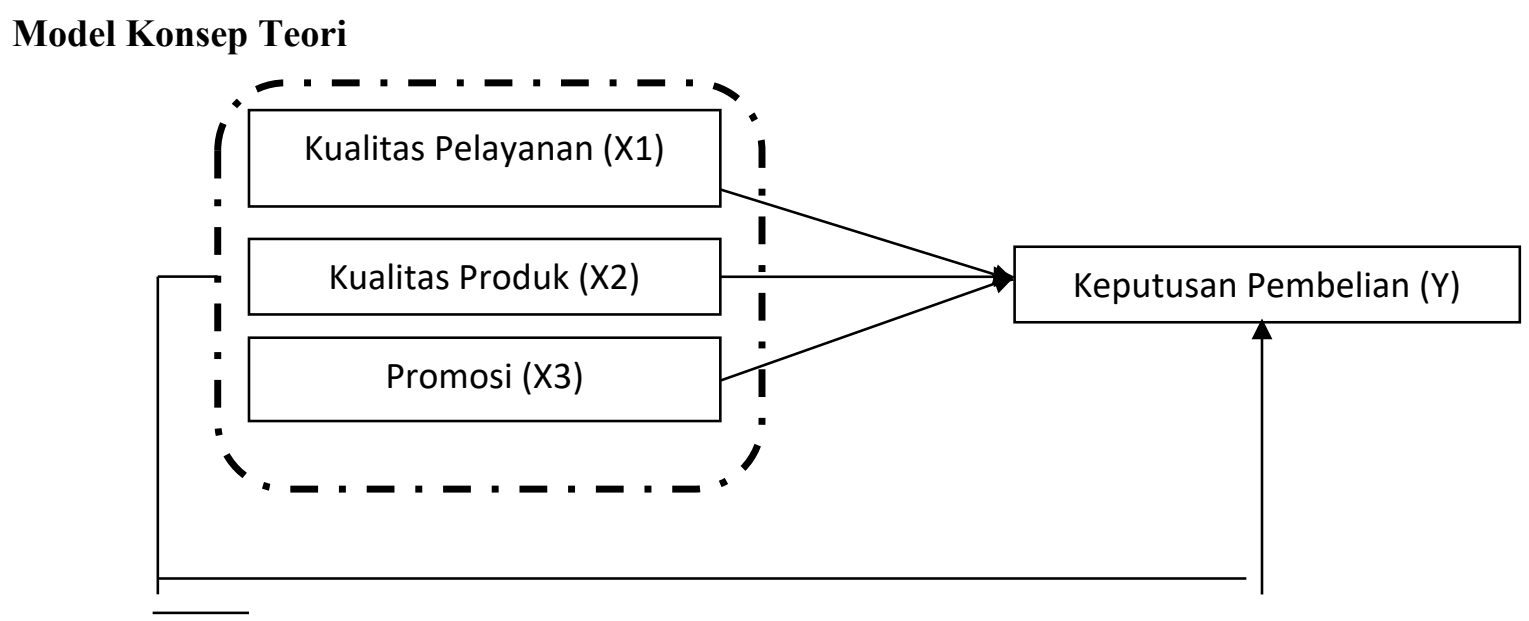

Hipotesis yang diajukan dalam penelitian ini adalah :

$\mathrm{Ho}_{1}$ : Kualitas Pelayanan tidak berpengaruh terhadap Keputusan pembelian.

$\mathrm{Ha}_{1}$ : Kualitas Pelayanan berpengaruh terhadap Keputusan Pembelian.

$\mathrm{Ho}_{2}$ : Kualitas Produk tidak berpengaruh terhadap keputusan Pembelian.

$\mathrm{Ha}_{2}$ : Kualitas Produk berpengaruh terhadap Keputusan pembelian.

$\mathrm{Ho}_{3}$ : Promosi tidak berpengaruh terhadap Keputusan Pembelian.

$\mathrm{Ha}_{3}$ : Promosi berpengaruh terhadap Keputusan Pembelian.

$\mathrm{Ho}_{4}$ : Kualitas Pelayanan, Kualitas Produk dan Promosi tidak berpengaruh terhadap Keputusan Pembelian.

$\mathrm{Ha}_{4}$ : Kualitas Pelayanan, Kualitas Produk dan Promosi berpengaruh terhadap keputusan pembelian.

\section{Metode Penelitian.}

\section{Populasi dan Sampel}

Populasi dalam penelitian ini adalah seluruh pembeli yang mengunjungi Optik Tunggal Sempurna cabang Lippo Mall Kemang. Adapun tehnik penentuan sampling dalam penelitian ini adalah tehnik sampling incidental.Sampel adalah bagian dari jumlah dan karakteristik yang dimilki oleh populasi tertentu. Dalam penelitian ini akan menggunakan sampel sebanyak 58 responden.

\section{Desain Penelitian}

Dalam penelitian ini desain penelitian yang digunakan yaitu Penelitian Kausal, yaitu penelitian yang bertujuan untuk mengetahui pengaruh antara satu atau lebih variabel independen terhadap variabel dependen.

\section{Jenis dan sumber data}

Jenis data yang digunakan dalam penelitian ini adalah data Primer. Pengumpulan data primer dalam penelitian ini melalui cara menyebarkan kuesioner dan melakukan wawancara secara langsung dengan pihak-pihak yang berhubungan dengan penelitian yang dilakukan. 


\section{Definisi Operasional Variabel dan Skala Pengukurannya}

Variabel penelitian dan definisi operasioanal berdasarkan pada masalah hipotesis yang akan di uji sebagai berikut:

1. Variabel Bebas (Independent Variabel)

Variabel bebas adalah merupakan variabel yang mempengaruhi atau yang menjadi sebab perubahannya atau timbulnya variabel dependen

Variabel yang digunakan dalam peneletian adalah :

a). Kualitas Pelayanan

Kualitas jasa perusahaan diuji pada setiap pelaksanaan jasa.berdasarkan skala SERVQUAL terdapat lima determinan Kualitas Jasa yaitu Keandalan, Responsivitas, Jaminan, Empati, dan Wujud. Ada zona toleransi atau kisaran dimana dimensi jasa dianggap memuaskan. Ditandai dengan tingkat kesedian minimum konsumen untuk menerima dan tingkat dimana mereka percaya bahwa jasa bisa dan harus dihantarkan kepada mereka.

b). Kualitas Produk .

Kualitas produk adalah kemampuan sebuah produk dalam memperagakan fungsinya, hal itu termasuk keseluruhan durabilitas, reabilitas, ketepatan, kemudahan pengoperasian dan reparasi produk juga atribut produk lainnya.

c). Promosi.

Promosi adalah berbagai cara untuk menginformasikan, membujuk dan mengingatkan konsumen secara langsung maupun tidak langsung tentang suatu produk atau brand yang dijual.

\section{Variabel Terikat (Dependent Variable)}

Variabel Dependen sering disebut sebagai variabel output, kriteria, konsekuen. Dalam bahasa Indonesia sering disebut sebagai variabel terikat. Variabel terikat merupakan variabel yang di pengaruhi atau yang menjadi akibat, karena adanya variabel bebas.

Dalam penelitian ini yang menjadi variable terikat adalah :

Keputusan pembelian : Keputusan pembelian konsumen merupakan keputusan pembelian konsumen akhir perorangan dan rumah tangga yang membeli barang dan jasa

Skala pengukuran untuk variabel-variabel dalam penelitian ini baik variabel independen maupun variabel dependen menggunakan skla interval.

\section{Metode Analisis}

\section{Analisis Deskripstif}

Analisis deskriptif adalah statistik yang digunakan untuk menganalisa data dengan cara mendeskripsikan atau menggambarkan data yang telah terkumpul sebagaimana adanya tanpa bermaksud membuat kesimpulan yang berlaku untuk umum atau generalisasi. 


\section{Uji asumsi klasik}

\section{- Uji Normalitas}

Metode normalitas grafik, yaitu dengan melihat penyebaran data pada sumber diagonal pada grafik Normal $P-P$ of regression standardized. Jika titik-titik menyebar sekitar garis diagonal, maka nilai residual tersebut telah normal.

\section{- Uji Multikoleniaritas}

Konsekuensi adanya multikolinieritas adalah koefisien korelasi tidak tertentu dan kesalahan menjadi sangat besar

\section{- Uji Autokorelasi}

Uji Autokorelasi merupakan korelasi antara anggota observasi yang disusun menurut waktu atau tempat. Model regresi yang baik seharusnya tidak terjadi autokorelasi. Metode pengujian menggunakan uji Durbin-Watson (DW test).

\section{- Uji Hetroskedastisitas}

Uji Heteroskodastisitas adalah varian residual yang tidak sama pada semua pengamatan di dalam model regresi. Regresi yang baik seharusnya tidak terjadi Heteroskedastisitas.

\section{- Uji Korelasi}

Nilai koefisien korelasi berkisar antara 0 sampai 1 atau 0 sampai -1 . Nilai semakin mendekati 1 atau -1, maka hubungan semakin erat .Nilai mendekati 0 maka hubungan semakin lemah.

\section{- Uji Regresi Linier Berganda}

Regresi linier berganda digunakan untuk memprediksi pengaruh lebih dari satu variable bebas (independent) terhadap satu variable terikat (dependent)

Rumus : $\mathrm{Y}=\mathrm{a}+\mathrm{b} 1 \mathrm{X} 1+\mathrm{b} 2 \mathrm{X} 2+\mathrm{b} 3 \mathrm{X} 3+\mathrm{e}$

\section{- Uji t}

Uji t yaitu suatu uji untuk mengetahui apakah dalam model regresi variabel independen secara parsial berpengaruh signifikan terhadap variabel dependen yang di uji pada tingkat signifikansi 0,05 .

- Uji F

Uji F digunakan untuk mengetahui apakah variabel independen (X) secara bersama-sama berpengaruh signifikan terhadap variabel dependen (Y).

- $\quad$ Jika $\mathrm{F}$ hitung $\leq \mathrm{F}$ tabel maka Ho diterima

- $\quad$ Jika F hitung $>$ F tabel maka Ho ditolak

\section{- Uji Koefisien Determinasi $\left(\mathbf{R}^{2}\right)$}

Koefisien determinasi digunakan untuk menjelaskan proporsi variable dependen yang mampu dijelaskan oleh variasi variabel bebasnya (independent). Koefisien determinasi ditunjukkan melalui nilai adjusted $\mathrm{R}^{2}$, Koefisien determinasi $0<\mathrm{R}^{2}<1$. Nilai $\mathrm{R}^{2}$ yang kecil berarti kemampuan variable bebas hampir memberikan semua informasi yang dibutuhkan untuk memprediksi variable terikat. 


\section{PEMBAHASAN}

\section{Uji Asumsi Klasik}

\section{Hasil Uji Normalitas}

Pengujian Normalitas data dala penelitian ini menggunakan uji Kolmogorov-Smirnov. Dengan membandingkan nilai signifikan yang dicapai dengan taraf signifikansi yang sudah ditentukan 0,05. Berikut ini merupakan hasil uji normalitas.

\section{Tabel 3}

\section{Tests of Normality}

\begin{tabular}{|l|l|l|l|l|l|l|}
\hline \multirow{2}{*}{} & \multicolumn{4}{l|}{ Kolmogorov-Smirnov $^{\mathrm{a}}$} & \multicolumn{3}{l|}{ Shapiro-Wilk } \\
\cline { 2 - 7 } & Statistic & Df & Sig. & Statistic & df & Sig. \\
\hline Kualitas Pelayanan & .116 & 58 & $\mathbf{. 0 5 2}$ & .964 & 58 & .086 \\
Kualitas Produk & .115 & 58 & $\mathbf{. 0 5 4}$ & .918 & 58 & .001 \\
Promosi & .110 & 58 & $\mathbf{. 0 7 6}$ & .950 & 58 & .019 \\
Total Skor & .114 & 58 & $\mathbf{. 0 5 7}$ & .952 & 58 & .023 \\
\hline
\end{tabular}

a. Lilliefors Significance Correction

Sumber : Output spss 2018

\section{Gambar 2 Hasil Uji Heteroskesdastisitas}

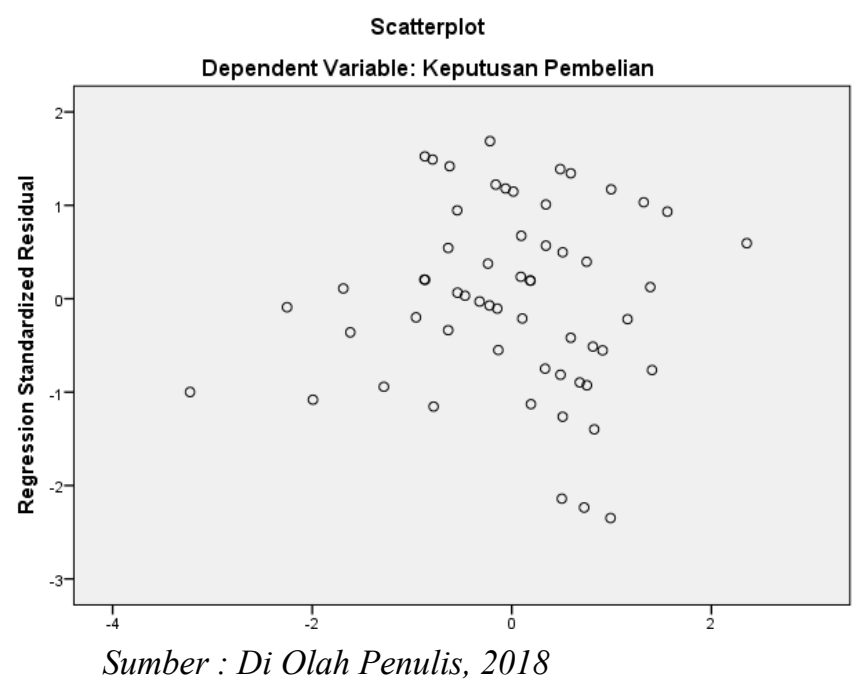

Gambar 2 menunjukan bahwa tidak ada pola yang jelas, serta titik-titik menyebar di atas dan di bawah angka 0 pada sumbu Y, maka tidak terjadi Heteroskedastisitas. 


\section{Uji Analisis Regresi Linier Berganda}

\section{Tabel 3 Hasil Analisis Regresi Linier Berganda}

\begin{tabular}{|c|c|c|c|c|c|c|c|}
\hline \multirow[b]{2}{*}{ Model } & \multicolumn{2}{|c|}{$\begin{array}{l}\text { Unstandardized } \\
\text { Coefficients }\end{array}$} & \multirow{2}{*}{$\begin{array}{l}\text { Standardized } \\
\text { Coefficients } \\
\text { Beta }\end{array}$} & \multirow[b]{2}{*}{$\mathrm{t}$} & \multirow[b]{2}{*}{ Sig. } & \multicolumn{2}{|c|}{ Collinearity Statistics } \\
\hline & $\mathrm{B}$ & Std. Error & & & & Tolerance & VIF \\
\hline 1 (Constant) & 21.995 & 4.567 & & 4.816 & .000 & & \\
\hline Kualitas Pelayanan & -.076 & .096 & -.123 & -.792 & .432 & .640 & 1.562 \\
\hline Kualitas Produk & .312 & .111 & .377 & 2.805 & .007 & .859 & 1.164 \\
\hline Promosi & .156 & .111 & .206 & 1.411 & .164 & .728 & 1.373 \\
\hline
\end{tabular}

a. Dependent Variable: Keputusan Pembelian

Sumber : Di Olah Penulis, 2018

$$
\mathrm{Y}=21.995-0,076 \times 1+0,312 \times 2+0,156 \times 3+e
$$

Hasil dari analisis persamaan regresi berganda tersebut dapat diintrerpretasikan sebagai berikut:

Nilai konstanta sebesar 21.995 jika kualitas pelayanan, kualitas produk dan promosi nilainya 0 , maka keputusan pembelian adalah 21.995. Koefisien regresi Kualitas pelayanan sebesar -0,076 artinya, Kualitas pelayanan menurun satu satuan maka Keputusan Pembelian akan mengalami penurunan sebesar $\mathbf{- 0 , 0 7 6}$ satuan. Koefisien regresi Kualitas Produk sebesar 0,312 artinya Kualitas Produk meningkat satu satuan maka Keputusan Pembelian akan mengalami kenaikan sebesar 0,312 satuan . Koefisien regresi Promosi sebesar 0,156 artinya, Promosi meningkat satu satuan maka Keputusan Pembelian akan mengalami kenaikan 0,156 satuan. Koefisien regresi Kualitas Pelayanan, Kualitas Produk, Promosi bertanda positif maka meningkatkan prediksi keputusan pembelian ulang juga akan meningkatkan karena terjadi pengaruh yang positif atau secara antara variabel bebas dengan variabel terikat.

\section{Uji t}

\section{Tabel 4 Hasil Uji t}

\section{Coefficients $^{\mathrm{a}}$}

\begin{tabular}{|c|c|c|c|c|c|c|c|c|}
\hline \multirow{2}{*}{\multicolumn{2}{|c|}{ Model }} & \multicolumn{2}{|c|}{$\begin{array}{l}\text { Unstandardized } \\
\text { Coefficients }\end{array}$} & \multirow{2}{*}{$\begin{array}{l}\text { Standardized } \\
\text { Coefficients } \\
\text { Beta }\end{array}$} & \multirow[b]{2}{*}{$\mathrm{T}$} & \multirow[b]{2}{*}{ Sig. } & \multicolumn{2}{|c|}{ Collinearity Statistics } \\
\hline & & $\mathrm{B}$ & Std. Error & & & & Tolerance & VIF \\
\hline \multirow[t]{4}{*}{1} & (Constant) & 21.995 & 4.567 & & 4.816 & .000 & & \\
\hline & $\begin{array}{l}\text { Kualitas } \\
\text { Pelayanan }\end{array}$ & -.076 & .096 & -.123 & -.792 & .432 & .640 & 1.562 \\
\hline & Kualitas Produk & .312 & .111 & .377 & 2.805 & .007 & .859 & 1.164 \\
\hline & Promosi & .156 & .111 & .206 & 1.411 & .164 & .728 & 1.373 \\
\hline
\end{tabular}

a. Dependent Variable: Keputusan Pembelian

Sumber : Di Olah Penulis, 2018

Tabel 4 menunjukan bahwa Variabel Kualitas Pelayanan $t_{\text {hitung }}$ yakni $\mathbf{- 0 , 7 9 2}<\mathbf{1 , 6 7 3}$. Pengambilan keputusan dapat dilakukan dengan melihat probabilitasnya dimana nilai $\mathbf{0 , 4 3 2}>$ 0,05 sehingga $\mathrm{H}_{\mathrm{a}}$ ditolak $\mathrm{H}_{\mathrm{o}}$ diterima, maka variabel Kualitas Pelayanan secara signifikan tidak 
berpengaruh nyata terhadap Keputusan Pembelian pada Optik Tunggal Sempurna. Variabel Kualitas Produk $t_{\text {hitung }}$ yakni 2.805 $>$ 1.673. Pengambilan keputusan dapat dilakukan dengan melihat probabilitasnya dimana nilai $\mathbf{0 , 0 0 7}<\mathbf{0 , 0 5}$ sehingga $\mathrm{H}_{\mathrm{a}}$ diterima $\mathrm{H}_{\mathrm{o}}$ ditolak, maka variabel Kualitas Produk secara signifikan berpengaruh nyata terhadap Keputusan Pembelian pada Optik Tunggal Sempurna. Variabel Promosi thitung yakni $1.411<\mathbf{1 . 6 7 3}$. Pengambilan keputusan dapat dilakukan dengan melihat probabilitasnya dimana nilai 0,164 $>\mathbf{0 , 0 5}$ sehingga $\mathrm{H}_{\mathrm{a}}$ ditolak $\mathrm{H}_{\mathrm{o}}$ diterima, maka variabel Promosi secara signifikan tidak berpengaruh nyata terhadap Keputusan Pembelian pada Optik Tunggal Sempurna.

\section{Uji F}

\section{Tabel 5 Hasil Uji F}

ANOVA $^{\mathbf{a}}$
\begin{tabular}{|ll|l|l|l|l|l|}
\hline Model & Sum of Squares & Df & Mean Square & F & Sig. \\
\hline 1 & Regression & 53.040 & 3 & 17.680 & $\mathbf{3 . 4 2 7}^{\mathbf{2}}$ & $\mathbf{. 0 2 3}^{\mathbf{b}}$ \\
& Residual & 278.615 & 54 & 5.160 & & \\
& Total & 331.655 & 57 & & & \\
\hline
\end{tabular}

Sumber : Di Olah Penulis, 2017

Tebel 5 menunjukan bahwa keseluruhan variabel independen memiliki pengaruh yang signifikan terhadap variabel dependen. Maka dapat di simpulkan bahwa variabel kualitas pelayanan, kualitas produk dan promosi berpengaruh bersama-sama terhadap keputusan pembelian.

\section{Uji Koefisien Determinasi $\left(\mathbf{R}^{2}\right)$}

\section{Tabel 6 Hasil Uji Koefisien Determinasi $\left(\mathbf{R}^{2}\right)$}

Model Summary
\begin{tabular}{|l|l|l|l|l|l|}
\hline Model & R & R Square & $\begin{array}{l}\text { Adjusted } \\
\text { Square }\end{array}$ & $\begin{array}{l}\text { Rtd. Error of the } \\
\text { Estimate }\end{array}$ & Durbin-Watson \\
\hline 1 & $.400^{\mathrm{a}}$ & .160 & .113 & 2.271 & 2.103 \\
\hline
\end{tabular}

a. Predictors: (Constant), Promosi, Kualitas Produk, Kualitas Pelayanan

Sumber : Di Olah Penulis, 2018

Tabel 6 menunjukan bahwa nilai $\mathrm{R}^{2}$ sebesar 0,113 (11,3\%), Ini menunjukan bahwa dengan menggunakan model regresi yang didapatkan dimana variabel independen yaitu kualitas pelayanan, kualitas produk dan promosi memiliki pengaruh terhadap variabel keputusan pembelian sebesar $11,3 \%$. Sedangkan sisanya $88,7 \%$ dijelaskan dengan faktor atau variabel lain yang tidak diketahui dan tidak termasuk dalam analisis regresi ini.

\section{PEMBAHASAN}

\section{Pengaruh Variabel Kualitas Pelayanan terhadap Keputusan Pembelian.}

Kualitas Pelayanan adalah upaya pemenuhan kebutuhan dan keinginan pelanggan serta ketepatan penyampainnya untuk mengimbangi harapan pelanggan. Dalam penelitian ini Kualitas Pelayanan tidak berpengaruh terhadap Keputusan Pembelian. Hal ini tidak sesuai dengan teori yang menyatakan Kualitas pelayanan merupakan suatu keharusan yang dilakukan perusahaan agar dapat bertahan dan Perusahaan harus terus menigkatkan kualitas pelayanannya sebab 
kualitas merupakan hal yang sangat sulit di ukur dan dijabarkan jika di bandingkan dengan kualitas produk. Pembeli disini membandingkan setiap pelayanan yang ada di setiap optik dan pelayanan yang baik akan membuat pembeli nyaman dan akan menimbulkan rasa di hargai dan dihormati sebgai seorang pembeli. Hal ini sesuai dengan penelitian sebelumnya yang dilakukan oleh Rahmi Rosita (2016) yang berjudul " Pengaruh lokasi, kelengkapan produk, kualitas produk, pelayanan, harga, dan kenyamanan berbelanja terhadap minat beli ulang konsumen pada lotte mart bekasi junction yang menyatakan bahwa variable pelayanan tidak berpengaruh terhadap minat beli ulang konsumen di Lotte Mart Bekasi Junction.

\section{Pengaruh Variabel Kualitas Produk terhadap Keputusan Pembelian}

Kualitas produk merupakan hal yang sangat penting bagi perusahaan. Seseorang atau organisasi memuaskan keinginan dan kebutuhannya melalui produk. Kualitas Produk merupakan produk yang ditawarkan oleh penjual mempunyai nilai jual lebih yang tidak dimiliki oleh produk pesaing. Produk yang di tawarkan PT.Optik Tunggal Sempurna menjual produk lensa yang tidak dimiliki oleh pesaing yaitu merek lensa Carl Zeiss dari German yang merupakan lensa kualitas nomer satu di dunia digunakan pada kamera CLR pada merek kamera Canon dan Nikon dan digunakan di kamera satelit NASA dan terdapat lapisan lensa yang Hydrophobic yaitu lapisan air dan debu tidak akan menempel ke lensa, terdapat design lensa yang dapat di sesuaikan dengan kebutuhan pembeli. Jadi, dapat di simpulkan bahwa Kualitas Produk dari PT. Optik Tunggal Sempuna dapat mempengaruhi Keputusan Pembelian. Hal ini sesuai dengan penelitian sebelumnya yang dilakukan oleh Novemy Triyandari Nugroho (2015) yang berjudul " Analisis Pengaruh Kualitas Produk, Harga dan Promosi terhadap Keputusan Pembelian Air Miniral Kemasan." Menyatakan bahwa Kualitas Produk berpengaruh secara signifikan terhadap Keputusan Pembelian air mineral kemasan.

\section{Pengaruh Variabel Promosi Terhadap Keputusan Pembelian}

Promosi adalah berbagai cara menginformasikan, membujuk dan menginginkan konsumen secara langsung maupun tidak langsung tentang suatu produk atau brand yang dijual. Dalam penelitian ini Promosi tidak berpengaruh terhadap Keputusan pembelian di PT.Optik Tunggal Sempurna Karena pembeli membandingkan promosi yang ada dengan pesaing lainnya. Perusahaan sebaiknya terus mempertimbangkan dan meningkatkan promosi yang ada guna meningkatkan Keputusan Pembelian. Hal ini sesuai dengan penelitian sebelumnya yang dilakukan oleh Maulana M.I.Umaternate, Willem JF.Alfa Tumbuan, Rita Taroreh(2014) yang berjudul " Promosi, Harga, dan Inovasi terhadap Keputusan Pembelian Sepatu Futsal Nike Di Toko Akbar Ali Sport Manado yang menyatakan bahwa Promosi tidak memiliki pengaruh yang signifikan terhadap Keputusan Pembelian Sepatu Futsal Nike di Toko Akbar Ali Sport.

\section{PENUTUP}

Berdasarkan hasil pengujian dan pembahasan maka dapat disimpulkan Kualitas Pelayanan, Kualitas Produk dan Promosi secara simultan berpengaruh terhadap Keputusan Pembelian pada Optik Tunggal Sempurna. Hasil penelitian secara parsial menunjukan Variabel

Kualitas Produk berpengaruh terhadap Keputusan Pembelian sementara Variabel Kualitas Pelayanan dan Promosi tidaak berpengaruh terhadap Keputusan Pembelian.

\section{Saran}

Berdasarkan pada kesimpulan yang telah diuraikan diatas, saran yang mungkin dapat dijadikan pertimbangan dan masukkan adalah sebagai berikut: 


\section{Bagi Perusahaan}

Lebih meningkatkan pelayanan dari segi ketepatan dan kecermatan yang dijalankan dan selalu memberikan yang terbaik kepada konsumen mengetahui kebutuhan yang di inginkan dan dapat bersaing di pasar global menjual barang-barang yang berkualitas tinggi dan memiliki inovasi baru yang tidak dimiliki pesaing serta selalu terus mengadakan kegiatan promosi yang efektif guna menarik minat beli konsumen agar perusahaan dapat maju dan berkembang.

2. Bagi Akademisi

Penelitian ini diharapkan menjadi sumber ilmu pengetahuan sehingga dapat menjadi bahan bacaan yang berguna bagi pembaca dan juga dapat dimanfaatkan sebagai bahan referensi bagi penelitian selanjutnya dan disarankan untuk meneliti variabel-variabel lain selain Kualitas Pelayanan, Kualitas Produk dan Promosi.

\section{DAFTAR PUSTAKA}

Buchari Alma, 2011, Manajemen Pemasaran dan Pemasaran Jasa, Penerbit Alfabeta Bandung. Daryanto, 2011, Manajemen Pemasaran, Cetakan 1, PT. Sarana Tutorian Nurani Sejahtera, Bandung

Duwi Priyatno, 2014 SPSS 22: Pengelolaan Data Terpraktis, Penerbit ANDI OFFSET, Yogyakarta.

Philip Kotler dan Gary Armstrong, 2014. Priciples of Marketing. Edisi 14, Pearson Education Limited, England

Philip Kotler dan Kevin Keller, 2012. Manajemen Pemasaran. Edisi 13 Jilid 2. Terjemahan Oleh Bob Sabran, Jakarta

Philip Kotler dan Kevin Keller, 2016. Marketing Management, Edisi 15, Pearson Education Limited, England

Sugiyono. 2016. Metode Penelitian Kuantitatif Kualitatif dan R\&D. Bandung: Alfabeta Tjiptono, Fandy dan Gregorius Chandra. 2014. Pemasaran Strategik. Yogyakarta: Andi Tjiptono, Fandy dan Gregorius Chandra. 2016. Service, Quality \& Satisfaction Edisi 4. Yogyakarta: Andi

Wijaya, Toni 2013 Metedologi Penelitian : Ekonomi dan Bisnis Teori Praktis, Jakarta : Graha Ilmu

Yamit, Zulian. 2013. Manajemen Kualitas Produk dan Jasa. Yogyakarta: Ekonisia.

Josiel Driand Pandensolang(2015) deengan judul Pengaruh Diferensiasi, Kualitas Produk dan Ekuitas Merek terhadap Keputusan Pembelian Coca-Cola pada PT. Bangun Wenang Beverges Company di Manado

Maulana M.I.Umaternate, Willem JF.Alfa Tumbuan, Rita Taroreh(2014) yang berjudul Promosi, Harga, dan Inovasi terhadap Keputusan Pembelian Sepatu Futsal Nike Di Toko Akbar Ali Sport Manado

Novemy Triyandari Nugroho(2015) dengan judul Analisis Pengaruh Kualitas Produk, Harga Dan Promosi Terhadap Keputusan Pembelian Air Mineral Kemasan.

Rahmi Rosita (2016) dengan judul Pengaruh lokasi, kelengkapan produk, kualitas produk, pelayanan, harga, dan kenyamanan berbelanja terhadap minat beli ulang konsumen pada lotte mart bekasi junction. 